\title{
A Review on the Models of Organizational Effectiveness: A Look at Cameron's Model in Higher Education
}

\author{
Giti Ashraf (Corresponding author) \\ Faculty of Educational Studies, University Putra Malaysia \\ 43400, Serdang, Selangor, Malaysia \\ Tel: 60-111-541-6940Ｅ-mail: GS22072@mutiara.upm.edu.my
}

\author{
Suhaida bte Abd Kadir \\ Faculty of Educational Studies, University Putra Malaysia \\ 43400, Serdang, Selangor, Malaysia
}

Tel: 60-389-468-140Ｅ-mail: suhaida@educ.upm.edu.my

Received: October 24, 2011 Accepted: November 3, $2011 \quad$ Published: April 1, 2012

doi: $10.5539 /$ ies.v5n2p80

URL: http://dx.doi.org/10.5539/ies.v5n2p80

\begin{abstract}
Organizational effectiveness is the main concern of all higher education institutes. Over the years there have been many different models of effectiveness along with the criteria for measuring organizational effectiveness. In this paper, four main models of organizational effectiveness namely the goal approach, the system resource approach, the process approach and the strategic constituency approach are reviewed. Moreover, this paper introduces several models of organizational effectiveness in higher education. Then, a brief review is made on some empirical studies that used the Cameron's (1978) model of organizational effectiveness. In the end, the paper suggests that Cameron's (1978) model seems the most appropriate for studying organizational effectiveness in higher education.
\end{abstract}

Keywords: Cameron's (1978) model, Higher education, Organizational effectiveness model

\section{Organizational Effectiveness}

In the 1980s, organizational effectiveness became more prominent and switched to being a concept from the status of a construct (Henry, 2011). This concept is related to issues such as the ability of an organization to access and absorb resources and consequently achieve its aims (Federman, 2006). As Gigliotti (1987) said, a unit which is individually ineffective in terms of cooperation with the rest of the organization is doomed to failure. Cameron (1978) pointed out that organizational effectiveness is the proficiency of the organization at having access to the essential resources. However, McCann (2004) noted it as the criterion of the organization's successful fulfillment of their purposes through core strategies.

Vinitwatanakhun's (1998) study illustrated that organizational effectiveness should focus on human resources and organizations and help individuals to achieve skills and self-esteem in order to control the new environment and find security and support. As Baker and Branch (2002) pointed out, the organizations, laboratories and universities that are involved in scientific researches suffer most, because they have to present effective management, behave more responsibly, and do jobs with limited resources in order to improve their effectiveness. Although willing to improve their effectiveness, the managers in these organizations first see themselves as scientists and then managers. However, they have to deal with the problems of the organization and system effectiveness. They are obliged to be innovative in their research, conduct, sponsorship as well as design and management of their organizations.

In the literature, there is not a single model of organizational effectiveness to fit all organizations. According to Balduck and Buelens (2008), the issue of effectiveness in organizations revolves round four main approaches: the system resource approach, the goal approach, the strategic constituency approach and the internal process approach. These are effective and efficient approaches which are contingent upon the type of situation to arise. This paper deals with the characteristics of the four models of organizational effectiveness as referred to below. 


\section{Main Models of Organizational Effectiveness}

\subsection{The Goal Approach}

The first extensively used approach in organizational effectiveness is the goal approach. Its focus is on the output to figure out the essential operating objectives like profit, innovation and finally product quality (Schermerhorn, Hunt, R. N. Osborn, \& R. Osborn, 2004). There are some basic assumptions for the goal approach. One of them is that there should be a general agreement on the specific goals and the people involved should feel committed to fulfilling them. The next assumption is that the number of goals is limited and achieving them requires certain indispensable resources (Robbins, 2003). As Altschuld and Zheng (1995) said the weakened significance of the goal-based approach for the evaluation of the effectiveness of research organizations and academic establishments is depicted in the accurate and clear measurement of the results. In fact, it is crucial in the vividness of the goals and output measures. The goal model is suitable only when these conditions are met. However, this is not usually applicable for the educational research organizations specifically in conditions where they are responsible to the goals and there must be justifications for their large-scale social functions. Moreover, any research possesses an exploratory nature and for the job of inquiry, freedom is essential. These are the facts which must not be restricted by narrow goals. In this case, the goal-oriented approach will be only partly suitable.

\subsection{The System Resource Approach}

The second approach is named the system resource approach which pays attention to the input of the figure. It explains the effectiveness from the point of view of the ability to obtain necessary resources from the environments outside the organization (Schermerhorn et. al., 2004). The application of system resource can be effective if a vivid relation exists between the resources which an organization receives and the goods or services it produces (Cameron, 1981). This approach invites managers to consider the organization not only as a whole but as a part of a larger group as well. The dominating attitude is that any part of the activities of an organization has an effect on all other parts (Mullins, 2008). In addition, due to their quantitative features, the uses of input and output measures of effectiveness in the system resource approach seem appealing. However, they will not actually display the entire story of performance, because it is not possible for new thoughts and discoveries to have an immediate and directly observable effect. It is also possible that the academic and research organizations will not give out outstanding results even after a long period of funding. Considering the prospect of making remarkable contributions in the future, and even though there may be no adequate evidence of effectiveness, founders may go on offering support (Altschuld \& Zheng, 1995).

\subsection{The Process Approach}

The third approach is known as the process approach which pays attention to the transformation process and is dedicated to seeing to what extent the resources are officially used to give services or produce goods (Schermerhorn et. al., 2004). By effectiveness, it is meant that the organization is internally healthy and efficient and the internal processes and procedures in that place are quite well-oiled. In an effective organization, there is no trace of stress and strain. The members are completely part of the system and the system itself works smoothly. The relationship between the members is based on trust, honesty, and good will. Finally, the flow of information is on a horizontal and vertical basis (Cameron, 1981). The trend of this approach in higher educational institutions is to fulfil the objectives by providing timely and sufficient information to the students, and the academicians. The collection of information and communication management is of major importance here (Kleijnen, Dolmans, Muijtjens, Willems, \& Van Hout, 2009).

\subsection{The Strategic Constituency Approach}

The fourth approach is the strategic constituency approach. It deals with the effect of the organization on the main stakeholders and their interests (Schermerhorn et. al., 2004). Based on this approach, effectiveness refers to the minimal satisfaction of all of the strategic constituencies of the organization. Strategic constituency involves all the people that are somehow connected to the organization. These people may have different roles such as the users of the services or products of the organization, the resource providers, the facilitators of the organization's output, the main supporters and the dependents of the organization (Cameron, 1981). T. Dalton and L. Dalton (1988) noted that in academic and research environments in which it is not quite easy to define the cost-benefit relations, it is sensible to make use of the strategic constituency approach. This approach assumes an exhaustive attitude toward effectiveness and evaluates the factors both in the environment and within the organization. In this outlook, the concept of social responsibility is taken into consideration. This is the notion that was not formally paid attention to in the traditional approaches, but it is of crucial importance for academic and research institutions which are financially supported by national money. Policy makers continuously pay attention to social responsibility because the resources which are available for research and development have been growing smaller and smaller at all levels 
of organizations. Therefore, in order to evaluate how answerable an organization is to the society, there rises the question of accountability of research activities and outcomes in relation to public expectations.

Besides these approaches, the legitimacy model, and the ineffectiveness model are involved, dealing with some dimensions of the general issue of organizational effectiveness (Altschuld \& Zheng, 1995). Although based on Cameron's (1978) description many different effectiveness models and approaches have evolved, there have been few studies on organizational effectiveness in higher education settings. Likewise Karagoz and Oz (2008) pointed out that there is a shortage of research in this regard. However, in the current paper, a review will be conducted of the attempts made in order to study organizational effectiveness at the higher education.

\section{Organizational Effectiveness Models at Higher Education}

Organizational effectiveness is an extensively researched topic (Rojas, 2000) and according to Karagoz and Oz (2008), work on organizational effectiveness started in the 1930's, later expanded by many theories and approached in the 1970's and onward. Different indicators most of which had similar views have been adopted to evaluate organizational effectiveness in higher education as the following:

\subsection{Antia and Cuthbert (1976)}

Based on Antia and Cuthbert's (1976) qualitative model, there are nine critical success factors in an institutional performance. These parameters have a tight relationship with each other; that is, if achievement is not granted due to one parameter, it could, later, negatively affect the total functioning. The nine factors are as follows: 1) social tune, 2) cost effectiveness, 3) course development, 4) corporate reputation, 5) investment in human capital, 6) physical facilities development, 7) student relations, 8) the quality of employee relations, and 9) public responsibility. Based on this model, measuring the effectiveness of an institution is a multi-dimensional issue. Organizational effectiveness can be appropriately evaluated from different points of view such as role effectiveness, efficiency, and potential capability for the future activities. Nine critical success factors need to be spotted and comparatively emphasized by any institution. Achievement in these areas is the sign of survival and growth.

\subsection{Kleeman and Richardson (1985)}

Employing a group of measures named "Effectiveness Field Criteria", Kleeman and Richardson (1985) studied students' perceptions of effectiveness in three state universities in Arizona following certain survey procedures. The instrument integrated ten factors or activity domain categories into the list of 54 activity statements. The study population included 3308 students at three universities. In their views, effectiveness in organization at higher levels of education is classified into ten categories: 1) programs and services for students, 2) attention to women and minorities, 3) quality of teaching and research, 4) publication of knowledge and research, 5) workshops and counseling to broaden access, 6) sports, 7) focus on cultural activities, 8) programs for graduates, 9) leasing facilities, and 10) enhancement of standards. At the end of this research, the writers concluded that students believe that such notions as the improvement of the services and programs for students, the efficiency of education and research and finally the offering of programs for graduates are of such high quality that they should be seriously developed at universities.

\subsection{Pounder (1999)}

In his model, Pounder (1999) introduced nine aspects for the evaluation of organizational effectiveness in Hong Kong academic institutions. These dimensions are as follows: 1) productivity-efficiency, 2) quality, 3) cohesion, 4) adaptability-readiness, 5) information management-communication, 6) growth, 7) planning-goal setting, 8) human resource development, and 9) stability-control. The study group comprised the administrative and academic staff from 7 institutions. According to Pounder (1999), the result of the study indicated improvement in the scales for reliable and valid self-rating in such dimensions as planning-goal setting, information management-communication, cohesion and productivity-efficiency. He also believed that these four dimensions of effectiveness can possibly be the main aspects of an organizational effectiveness model for Hong Kong's higher education. This is because there is a high degree of participation and good progress in the scale development procedure.

\subsection{An, Yom, and Ruggiero (2011)}

Furthermore, An et. al. (2011) assessed organizational effectiveness in terms of two dimensions: 1) job satisfaction, and 2) organizational involvement. In their study, a self-administered questionnaire was completed by a group of 145 nurses serving in Korean university hospitals. The results indicated that quality of career and intact organizational culture for nurses will certainly bring boosted organizational effectiveness. The study suggested that desired patient outcomes cannot be achieved without effective and efficient nursing care.

In another study, Cameron (1978) a model was devised for the evaluation of organizational effectiveness in higher 
education. Literature review shows that this model more than others has been considered by researchers in this field (e.g. Gigliotti, 1987; Hertelendy, 2010; Kwan \& Walker, 2003; Lejeune \& Vas, 2009; Smart, 2003; Vinitwatanakhun, 1998). Thus, the present paper aims to review the model, and provide some evidence for its suitability in organizational effectiveness assessment at higher education areas.

\section{Cameron's Model of Organizational Effectiveness}

In Cameron's (1978) proposal for the organizational effectiveness of 4-year colleges, there are nine dimensions and a 57-item questionnaire to secure the members' perceptions about the efficacy of their institutions on these aspects. Cameron's selection of these dimensions is based on the careful study of the criteria, institutions and constituencies, and an in-depth analysis (Siddiqui, 2010). The following describes these nine dimensions:

1) Student educational satisfaction. It deals with the satisfaction of students with their educational experiences at the place where they are studying.

2) Student academic development. This dimension discusses the rate and extent of achievement, growth, and progress which the students have managed to gain at the institute. It also deals with opportunities for academic development which is given to them by the institution.

3) Student career development. It indicates the range of the students' occupational and vocational progress as well as the opportunities which are given to them by the institutions.

4) Student personal development. It refers to the extent of the students' progress in non-career, non-academic areas; in fact, they are on the social, cultural, and emotional basis. The opportunities which are offered by the institutions are also within this dimension.

5) Faculty and administrator employment satisfaction. This refers to the satisfaction that the administrators and the faculty members have with their jobs.

6) Professional development and quality of the faculty. This dimension talks about the range of work achievement and improvement of the faculty members as well as the extent of motives toward work progress which the organization provides.

7) System openness and community interaction. It displays the attention which is given to interaction with the external environment of the institution, the adaptation to it and the service given in that place.

8) Ability to acquire resources. This refers to the range of resources the organization can earn from the outside. They can include faculty members and students with high-quality, political recognition and financial aid.

9) Organizational health. It refers to the level of smooth functioning of the institution from the viewpoint of its processes and operations such as good-will and liveliness of the institution.

Furthermore, according to Cameron (1978), there are four main fields of organizational effectiveness which are compatible with the effectiveness dimensions. The following are the outlines:

1) The academic field which is concerned with the students' academic progress, professional development and the productivity of the lecturers as well as the potential to obtain resources.

2) The moral field. This deals with the student's educational satisfaction, the organizational health and the faculty and administrator employment satisfaction.

3) The external adaptation field which deals with the student's career progress and system openness and community interaction.

4) The extracurricular field discusses the single dimension of student's personal development. Later, Cameron incorporated the student's personal progress dimension into the academic field and deleted the last field.

Based on Cameron's (1981) article, the organizational effectiveness is multi-field; that is to say, the system resource model is very closely related to the external adaptation field at the higher educational institutions. There seems to exist some similarity between the process approach and the moral field. The goal model is also similar to the academic field. Since organizational effectiveness is a multidimensional field, it cannot be measured by a single model and so all the variables should be taken into consideration (Cameron, 1978). In addition, it is essential to take all the contextual factors into account before any organizational effectiveness criteria are selected. Due to the diversity of cultures across countries and even within the country, it is possible that one factor can work in one place, but it may fail in another.

\section{Validity and Reliability of Cameron's Organizational Effectiveness Instrument}

In Cameron's 57- item questionnaire, the organizational effectiveness is determined according to the scores obtained from a seven-point Likert scale between 1 and 7. Cameron (1981) did his study on 41 institutions with a sample of academic department heads and administrators. In his study, the internal consistency reliability for each of the nine 
dimensions ranging from 0.83 to 0.99 was determined. To support the validity of his model, Cameron (1986) introduced five predictor variables in his analysis 1) institutional demographics, 2) institutional strategy, 3) institutional structure, 4) institutional finances, and 5) external environment. He believed that these predictors were strongly connected to the long-term performance. Out of the forty-one first institutions included in his earlier project, twenty-nine agreed to participate. In a period of four years, two sets of regression analysis with such predictors as independent variables were administered: one with the nine dimensions as dependent variables and the other with some changes in these nine dimensions. The results showed that the nine dimensions could suggest effectiveness beyond a short-term horizon.

In addition, reliability of Cameron's organizational effectiveness questionnaire has been reported by several researchers. For example, Anderson (2000) reported Cronbach's alpha from 0.66 to 0.85; Smart (2003) found the coefficient alpha from 0.66 to 0.85 , and Lejeune and Vas (2009) calculated the Cronbach's alpha from 0.65 to 0.87 for each of the nine dimensions. Moreover, Kwan and Walker (2003) reported reliability alpha from 0.76 to 0.87 for seven dimensions of organizational effectiveness instrument in higher education institutes in Hong Kong. These results show that the Cameron's questionnaire is the right tool for measuring organizational effectiveness in higher education.

\section{The Application of Cameron's Model of Organizational Effectiveness in Empirical Studies}

There have been extensive international studies using the Cameron's model of organizational effectiveness. For instance, Anderson (2000) did a study in which the researcher utilized a 16-item Cameron's organizational culture instrument and a 36-item Cameron's organizational effectiveness questionnaire. The participants of the study were all full-time faculty members, administrative and professional staff from the Tennessee Community Colleges in the United States. The findings indicated that the four culture types which are clan, adhocracy, hierarchy and market, are significantly related to the organizational effectiveness in the Tennessee Community Colleges. The associations were found to be strong $(\mathrm{p}<.001)$ and positive. Additionally, it was revealed that the Cameron's instrument works as a valuable diagnostic tool in higher education and is associated with more familiar university assessment indicators. Regarding the findings, the researcher suggested college members to obtain specific actions to learn how to use aspects of the four culture-types in order to achieve the maximum performance on the nine dimensions of effectiveness.

By considering organizational effectiveness as a second-order construct, Kwan and Walker (2003) investigated the relative significance of different dimensions of organizational effectiveness in higher education. The second-order structure of organizational effectiveness is duly supported by the results of a study conducted on the academics in Hong Kong universities. The study indicated that the dimensions related to students were not as significant as those dealing with faculty employment and satisfaction. It also implied that the governing body had uneven influence on Hong Kong universities. Based on the research findings, Cameron's instrument was generally an efficient tool for the assessment of organizational effectiveness but the dimension of organizational health was a determinant and not an indicator of organizational effectiveness. As a result, the dimension of organizational health was excluded from the study.

In another study which was based on Cameron's competitive values model and Cameron's organizational effectiveness instrument, Smart (2003) concluded a research in which the effective organizational performance of community colleges was clearly tied to the nature of their organizational culture. To collect data, a survey method was administered among full-time faculty and administrators in a statewide system of 14 community colleges in U.S.A. According to the researcher's suggestion, the most effective campus culture is one that reflects a healthy balance of the four culture types (adhocracy, clan, hierarchy, and market) rather than a focus on only one or two of those culture types. The importance of campus leaders in the management and change of campus cultures was also another finding of the study.

In their survey, Lejeune and Vas (2009) assessed the perceived effect of an accreditation process on culture and organizational effectiveness. The sample included 31 deans and directors general of European Quality Improvement System (EQUIS) in accredited schools. According to the findings, there was a positive effect on some aspects of effectiveness. The study did not report any effect associated with the bureaucracy feature of culture. The dimensions bearing the highest perceived positive effects included 1) the social openness and community interaction 2) the programs development and quality of the faculty and 3), the ability to obtain resources. Specifically, there were two cultural aspects which were closely related to effectiveness: market and adhocracy. In the end, it seems that the cultural change created by accreditation was associated with a positive effect on performance. Cameron's model has been validated by all of the abovementioned empirical studies and so it is regarded as an efficient instrument for the assessment of the organizational effectiveness. 


\section{Conclusion}

Based on the literature review, the organizational effectiveness has long been the subject of numerous studies through different models. Nevertheless, a comparative result between some models of organizational effectiveness in higher education shows some overlapping. For instance, Yorke's (1987) study indicated some common features between Cameron's (1978) model and Antia and Cuthbert's (1976) model. Moreover, Kleeman and Richardson (1985) described some similarity between their model and Cameron's (1978) model. However, the trace of some of Cameron's nine dimensions can be observed in two other models developed by Pounder (1999) and An et. al. (2011) (see Table 1). This suggests the comprehensiveness of Cameron's model for the assessment of organizational effectiveness in higher education institutions.

In addition, regarding the main models of effectiveness, the Cameron's (1978) model has a close relationship with three main models, namely goal, system resource, and process. Cameron (1981) noted out that, it pays attention to the fact that the organization is effective as long as it can achieve the goals intended. It can obtain the resources from the environment, and it can get along with all of its system processes in terms of the performance of the organization. Based on this model, it should be taken into consideration that there is not one single suitable model for the assessment of the organizational effectiveness. Even though the organizations fulfill the criteria of each approach, they may be judged ineffective. This can reflect the ability of Cameron's multi-dimensional model for a deeper study of organizational effectiveness in higher education.

Despite the fact that in different situations some reforms in terms of number of items, dimensions and wording in the original questionnaire have been made by some researchers (e.g. Anderson, 2000; Kwan \& Walker, 2003; Lejeune \& Vas, 2009; Smart, 2003), the capacity of the model, and reliability and validity of its questionnaire are well documented. Considering the mentioned points, Cameron's model of organizational effectiveness seems quite suitable to be used for higher education studies.

\section{References}

Altschuld, J. W., \& Zheng, H. Y. (1995). Assessing the effectiveness of research organizations. Evaluation Review, 19(2), 197-216. http://dx.doi.org/10.1177/0193841X9501900205

An, J. Y., Yom, Y. H., \& Ruggiero, J. S. (2011). Organizational culture, quality of work life, and organizational effectiveness in Korean university hospitals. Journal of Transcultural Nursing, 22(1), 22-30. http://dx.doi.org/10.1177/1043659609360849

Anderson, J. A. (2000). Explanatory roles of mission and culture: Organizational effectiveness in Tennessee's community colleges. Unpublished PhD thesis. University of Mephis.

Antia, J. M., \& Cuthbert, R. E. (1976). Critical success factors in Polytechnic performance. Educational Management Administration \& Leadership, 5(14), 14-36. http://dx.doi.org/10.1177/174114327600500103

Baker, K., \& Branch, K. M. (2002). Concepts underlying organizational effectiveness: Trends in the organization and management science literature. Management Benchmark Study. USA: Office of Planning \& Analysis, Department of Energy

Balduck, A. L., \& Buelens, M. (2008). A two-level competing values approach to measure nonprofit organizational effectiveness. Working Papers of Faculty of Economics and Business Administration, Ghent University, Belgium.

Cameron, K. (1978). Measuring organizational effectiveness in institutions of higher education. Administrative Science Quarterly, 23, 604-632. http://dx.doi.org/10.2307/2392582

Cameron, K. (1981). Domains of organizational effectiveness in colleges and universities. Academy of Management Journal, 24 (1), 25-47. http://dx.doi.org/10.2307/255822

Cameron, K. (1986). A study of organizational effectiveness and its predictors. Management Science, 32(1), 87-112. http://dx.doi.org/10.1287/mnsc.32.1.87

Dalton, T., \& Dalton, L. (1988). The politics of measuring public sector performance. Promoting Productivity in the Public Sector (Macmillan).

Federman, M. (2006). Essay: Towards an effect-ive theory of organizational effectiveness. [Online] Available: http://whatisthemessage.blogspot.com/2006_03_01_archive.html

Gigliotti, L. (1987). An adaptation of Cameron's model of organizational effectiveness at the academic department level in two-year community colleges. Unpublished PhD theses. Syracuse University.

Henry, E. A. (2011). Is the influence of organizational culture on organizational effectiveness universal? An examination of the relationship in the electronic media (radio) service sector in the English speaking Caribbean. 
Unpublished $\mathrm{PhD}$ theses. University of Mississippi

Hertelendy, A. J. (2010). A survey of emergency medical services programs: National EMS education program accreditation and organizational effectiveness. Unpublished $\mathrm{PhD}$ theses. University of Mississippi Medical Center.

Karagoz, S., \& Oz, E. (2008). Organizational effectiveness in higher education; measures, measurement and evaluation. Paper presented at the EABR \& TLC Conferences Proceedings Rothenburg, Germany.

Kleeman, G. L., \& Richardson Jr, R. C. (1985). Student characteristics and perceptions of university effectiveness. Review of Higher Education, 9(1), 5-20.

Kleijnen, J., Dolmans, D., Muijtjens, A., Willems, J., \& Van Hout, H. (2009). Organisational values in higher education: Perceptions and preferences of staff. Quality in Higher Education, 15(3), 233-249. http://dx.doi.org/10.1080/13538320903343123

Kwan, P., \& Walker, A. (2003). Positing organizational effectiveness as a second-order construct in Hong Kong higher education institutions. Research in Higher Education, 44(6), 705-726. http://dx.doi.org/10.1023/A:1026179626082

Lejeune, C., \& Vas, A. (2009). Organizational culture and effectiveness in business schools: A test of the accreditation impact. Journal of Management Development, 28(8), 728-741. http://dx.doi.org/10.1108/02621710910985504

McCann, J. (2004). Organizational effectiveness: Changing concepts for changing environments. Human Resource Planning, 27(1).

Mullins, L. J. (2008). Essentials of organisational behaviour: Pearson Education.

Pounder, J. (1999). Organizational effectiveness in higher education. Educational Management Administration \& Leadership, 27(4), 389-400. http://dx.doi.org/10.1177/0263211X990274006

Robbins, S. P. (2003). Essentials of organizational behavior: Prentice Hall.

Rojas, R. R. (2000). A review of models for measuring organizational effectiveness among for-profit and nonprofit organizations. Nonprofit Management and Leadership, 11(1), 97-104. http://dx.doi.org/10.1002/nml.11109

Schermerhorn, J. R., Hunt, J. G., Osborn, R. N., \& Osborn, R. (2004).Core concepts of organizational behavior: John Wiley \& Sons Inc.

Siddiqui, A. (2010). Impact of academic leadership on faculty's motivation, and organizational effectiveness in higher education system. Paper presented at the 3rd International Conference on Assessing Quality in Higher Education, 6th $-8^{\text {th }}$. [Online] Available: http://www.icaqhe2010.org/publication_3rd.html (December 2010)

Smart, J. C. (2003). Organizational effectiveness of 2-year colleges: The centrality of cultural and leadership complexity. Research in Higher Education, 44(6), 673-703. http://dx.doi.org/10.1023/A:1026127609244

Vinitwatanakhun, M. W. (1998). Factors affecting organizational effectiveness of nursing institutes in Thailand. 1-5. [Online] Available: http://www.journal.au.edu/au_techno/2002/apr2002/article8.pdf

Yorke, D. (1987). Indicators of institutional achievement: Some theoretical and empirical considerations. Higher Education, 16(1), 3-20. http://dx.doi.org/10.1007/BF00139243 
Table 1. Similarity between Cameron's model dimensions and other models in higher education

\begin{tabular}{|c|c|c|c|c|}
\hline Cameron (1978) & $\begin{array}{l}\text { Antia and } \\
\text { Cuthbert } \\
(1976)\end{array}$ & $\begin{array}{l}\text { Kleeman and } \\
\text { Richardson (1985) }\end{array}$ & Pounder (1999) & An et. al. (2011) \\
\hline $\begin{array}{l}\text { Student Educational } \\
\text { Satisfaction }^{1}\end{array}$ & $\begin{array}{l}\text { Social tune } \\
\text { Cost }\end{array}$ & $\begin{array}{l}\text { programs and } \\
\text { services for } \\
\text { students } 1,2,3,4\end{array}$ & $\begin{array}{l}\text { Productivity-efficiency } \\
\text { Quality }\end{array}$ & $\begin{array}{l}\text { Job } \\
\text { satisfaction }^{5}\end{array}$ \\
\hline $\begin{array}{l}\text { Student Academic } \\
\text { Development }^{2}\end{array}$ & effectiveness & Attention to & Cohesion $^{9}$ & $\begin{array}{l}\text { Organizational } \\
\text { involvement }\end{array}$ \\
\hline $\begin{array}{l}\text { Student Career } \\
\text { Development }^{3}\end{array}$ & $\begin{array}{l}\text { Course } \\
\text { development }\end{array}$ & $\begin{array}{l}\text { women and } \\
\text { minorities }\end{array}$ & Adaptability-readiness & \\
\hline $\begin{array}{l}\text { Student Personal } \\
\text { Development }\end{array}$ & $\begin{array}{l}\text { Corporate } \\
\text { reputation }\end{array}$ & $\begin{array}{l}\text { Quality of teaching } \\
\text { and research }^{6}\end{array}$ & $\begin{array}{l}\text { Information } \\
\text { management-communication }\end{array}$ & \\
\hline $\begin{array}{l}\text { Faculty and } \\
\text { Administrator }\end{array}$ & $\begin{array}{l}\text { Investment in } \\
\text { human capital }\end{array}$ & $\begin{array}{l}\text { Publication of } \\
\text { knowledge and } \\
\text { research }\end{array}$ & Growth $^{8}$ & \\
\hline $\begin{array}{l}\text { Employment } \\
\text { Satisfaction }^{5} \\
\text { Professional }\end{array}$ & $\begin{array}{l}\text { Physical } \\
\text { facilities } \\
\text { development }\end{array}$ & $\begin{array}{l}\text { workshops and } \\
\text { counseling to } \\
\text { broaden access }\end{array}$ & $\begin{array}{l}\text { Planning-goal setting } \\
\text { Human resource } \\
\text { development }^{6}\end{array}$ & \\
\hline $\begin{array}{l}\text { Development and } \\
\text { Quality of the } \\
\text { Faculty }^{6}\end{array}$ & $\begin{array}{l}\text { Student } \\
\text { relations 1, 2, 3, } 4\end{array}$ & Sports & Stability-control & \\
\hline $\begin{array}{l}\text { System Openness } \\
\text { and Community }\end{array}$ & $\begin{array}{l}\text { Employee } \\
\text { relations } 5\end{array}$ & $\begin{array}{l}\text { Focus on cultural } \\
\text { activities }^{7}\end{array}$ & & \\
\hline Interaction $^{7}$ & $\begin{array}{l}\text { Public } \\
\text { responsibility }\end{array}$ & $\begin{array}{l}\text { Programs for } \\
\text { graduates }\end{array}$ & & \\
\hline $\begin{array}{l}\text { Ability to Acquire } \\
\text { Resources }^{8}\end{array}$ & & Leasing facilities $^{8}$ & & \\
\hline $\begin{array}{l}\text { Organizational } \\
\text { Health }^{9}\end{array}$ & & $\begin{array}{l}\text { Enhancement of } \\
\text { standards }\end{array}$ & & \\
\hline
\end{tabular}

Note:

- “Cohesion: This aspect of an organization's performance has to do with behavior that reflects the extent, to which it is concerned with staff morale, interpersonal relationships, teamwork and sense of belonging.

- Growth: This aspect of an organization's performance has to do with behavior that reflects the extent of its ability to secure external support, acquire resources and increase its capabilities.

- Human Resource Development: This aspect of an organization's performance has to do with behavior that reflects the extent to which it is responsive to the individual needs of its staff. It also has to do with the extent to which the institution facilitates participation in decision making. Additionally, this aspect is concerned with behavior relating to the hiring, training and development of staff' (Pounder, 1999, pp. 394-395) 